\title{
O ENVELHECIMENTO FEMININO ENTRE COSTURAS: O ATELIER COREOGRÁFICO COMO POSSIBILIDADE DE EXPERIÊNCIA
}

\author{
Vanessa Bellani Lyra \\ Universidade de Caxias do Sul \\ vblyra@ucs.br \\ Amanda Khalil Suleiman Zucco \\ Universidade de Caxias do Sul \\ akszucco@ucs.br
}

\section{Resumo}

O presente estudo aborda a temática do envelhecimento feminino e suas interfaces. Para tal, contou-se com a criação de um espaço educacional e artístico, conduzido pelos contornos da Dança Contemporânea, a que se chamou Atelier Coreográfico. O objetivo do estudo foi estruturar o Atelier Coreográfico para que se configurasse uma experiência. Quanto aos procedimentos metodológicos adotou-se a pesquisa-ação, que contou com entrevistas baseadas na técnica de grupos focais. Por fim, para interpretar os dados recolhidos, adotou-se a técnica da Análise de Discurso. O estudo nos possibilitou identificar que a vivência gerada a partir das aulas fez emergir uma nova experiência de vida para o grupo de participantes, sustentada por três pilares principais: a oportunidade, a liberdade, e o desafio. Este estudo foi realizado entre o período de agosto à dezembro de 2016.

Palavras-chave: Envelhecimento Feminino. Dança Contemporânea. Experiência.

\section{FEMALE AGING BETWEEN SEWINGS: THE COREOGRAPHIC ATELIER AS A POSSIBILITY OF EXPERIENCE}

\begin{abstract}
The present study addresses the theme of female aging and its interfaces. To this end, the creation of an educational and artistic space, led by the contours of the Contemporary Dance, was called Atelier Choreographic. The objective of the study was to structure the Choreographic Workshop to be an experience, in the sense described by Jorge Larrosa Bondía. As for the methodological procedures, the action research was adopted, with interviews based on the technique of focus groups. Finally, to interpret the collected data, the technique of Discourse Analysis was adopted. The study allowed us to identify that the experience generated from the lessons gave rise to a new life experience for the group of participants, supported by three main pillars: opportunity, freedom, and the challenge. This study was carried out between August and December 2016.
\end{abstract}

Keywords: Aging Female. Contemporary Dance. Experience.

\section{EL ENVEJECIMIENTO FEMENINO ENTRE COSTURAS: EL ATELIER COREOGRÁFICO COMO POSIBILIDAD DE EXPERIENCIA}

\section{Resumen}

Este estudio aborda el tema del envejecimiento femenino y sus interfaces. Con este fin, se dijo a la creación de un espacio educativo y artístico, dirigido por los contornos de la danza contemporánea, que fue llamado Atelier coreografía. El objetivo del estudio fue estructurar Coreográfico Atelier para que configurarlo en un experimento en el sentido descrito por Jorge Larrosa Bondia. En cuanto a los procedimientos metodológicos adoptado la investigación-acción, que incluyó entrevistas basado en la técnica de grupos focales. Por último, para interpretar los datos recogidos, se adoptó la técnica de análisis del discurso. El estudio permitió identificar que la experiencia genera a partir de las clases hicieron surgir una nueva experiencia de vida para el grupo de participantes, con el apoyo de tres pilares principales: oportunidad, la libertad, y el desafío. Este estudio se realizó entre el período de agosto a diciembre de 2016.

Palavras clave: Envejecimiento Femenino. Danza Contemporánea. Experiencia. 
O envelhecimento feminino entre costuras: o atelier coreográfico como possibilidade de experiência.

\section{PRIMEIROS PASSOS}

De caráter híbrido e transformador, a dança contemporânea não se define em técnicas ou movimentos específicos: ao invés disso, o intérprete/bailarino tem disposição de articular um pensamento do contexto com autonomia para construir suas próprias partituras coreográficas a partir de métodos e procedimentos de pesquisa. A contemporaneidade na dança diz respeito a um modo de percepção e existência, não limitada a uma produção técnica, mas que adota um corpo multicultural, que tem várias referências. Dessa maneira, a dança contemporânea surge da necessidade de revelar e refletir o estado do mundo contemporâneo, onde acaba por não se definir, tão pouco se codificar. Desse contexto, marcado pela fugacidade própria ao que é fluido e líquido (BAUMAN, 2004), emerge uma nova noção de corporeidade, que busca um sentido mais experimental, menos estratificado.

Nesse cenário contemporâneo, compreender o envelhecimento significa perceber a singularidade de cada etapa da vida; a unicidade de cada momento. Isto é, significa ver nesse corpo - o qual o tempo vem remodelando - sua forma de pensar e de se colocar na sociedade, e ainda, seus discursos, possibilidades e potencialidades. Pressupõe admitir que o tempo, considerado pela ótica da cronologia, vai limitar esse corpo nas situações mais simples e corriqueiras da vida diária. Pressupõe, na mesma medida, celebrar o fato de que esse mesmo tempo possibilitará a emergência um legado de experiências corporais intransferíveis.

De modo a contemplar a singularidade de cada corpo, marcado pelo processo de envelhecimento e suas condições inerentes, criou-se um grupo de dança destinado exclusivamente para o acolhimento de mulheres idosas, intitulado Atelier Coreográfico. Tal grupo estruturou-se para o desenvolvimento de aulas de dança contemporânea que propiciassem, juntamente com o processo coreográfico, a preparação e os ensaios para exposição da obra final. Dessa maneira, o Atelier Coreográfico realçou suas experiências e possibilitou o surgimento de outras. De modo a salientar movimentos, expressões, e outras linguagens corporais que pudessem permitir a fala desses corpos, os encontros constituíram-se em um verdadeiro "laboratório de experiências corporais".

Nesse sentido, esta pesquisa apresenta-se como uma tentativa acadêmica de que o Atelier Coreográfico se configure numa experiência, no sentido descrito por Jorge Larrosa Bondía (2011). Se para o autor, a experiência genuína requer o significado e o "atravessamento" de nós mesmos, o grupo em questão vem propor a estes corpos novas maneiras de se movimentar e expressar, a partir da dança contemporânea. Desses movimentos, espera-se o surgimento de novos significados e sentidos (auto)atribuídos ao corpo que dança e, que por esta razão, vive a relação 
O envelhecimento feminino entre costuras: o atelier coreográfico como possibilidade de experiência.

do tempo de ontem, no aqui e no agora. Para isso, a presente pesquisa contará com algumas questões norteadoras, que serão aqui percorridas: O Atelier Coreográfico se constitui numa verdadeira experiência para estas mulheres? Quais os sentidos atribuidos ao Atelier Coreográfico, pelas mulheres idosas, que o constituiram numa experiência?

Este estudo adota uma abordagem de pesquisa qualitativa (MINAYO, 2001) que incluiu quanto à prática, o método da pesquisa-ação (THIOLLENT, 1988), e a pesquisa de práticaartística (FORTIN, 2007). Para a coleta de dados, o presente estudo contou com entrevistas por meio da técnica de grupos focais (TRAD, 2009); a partir da observação participante (GERHARDT, 2009). Por fim, para interpretar os dados recolhidos, adotou-se a técnica da Análise de Discurso (ORLANDI, 2007).

\section{O CONCEITO DE EXPERIÊNCIA, EM JORGE LARROSA BONDÍA}

No olhar do pedagogo espanhol Jorge Larrosa Bondía (2011, p. 5), a experiência poderia ser explicada pela seguinte frase: “isso que me passa". Diante desta frase ele apresenta uma descrição em três dimensões relacionando-as com a origem e a etimologia da palavra experiência na qual esmiuçaremos melhor a seguir.

A primeira questão seria a partir da palavra isso, que supõe necessariamente para a experiência um acontecimento, uma passagem de algo que não sou eu. Para Teixeira e Portner (2013) a ideia de Larrosa (2011, p. 101) demostra que a experiência "será aquilo que nos transpassa, atravessa pelo interior do homem onde deixará alguma marca, sinônimo de acontecimento". Ou seja, algo que não depende de mim, ou do meu poder, nem do meu saber, que não é uma projeção de mim mesmo, que está fora, isto é, que não sou eu, mas, "outra coisa que eu” (Bondía, 2011, p. 5). Se Larrosa (2011) coloca que a experiência é isso que me passa, o faz pelo motivo de que ele expõe e esclarece três princípios básicos para isso, a saber: "princípio da exterioridade", "princípio de alteridade" e "princípio de alienação".

A segunda questão de reflexão se desenvolve a partir do pronome pessoal oblíquo me. Dentro daquilo que já foi anteriormente apresentado, a experiência supõe que seja um acontecimento exterior a mim, mas pede num segundo momento algo que me passa, pois o lugar desta experiência sou eu. É em mim, através das minhas palavras, pensamentos, vontades, representações, etc, que a experiência terá lugar. Por sua vez, Larrosa (2011) define três outros princípios que detalham melhor: o primeiro - "princípio da reflexividade", o segundo - "princípio da subjetividade", o terceiro e último - "princípio da transformação". 
O envelhecimento feminino entre costuras: o atelier coreográfico como possibilidade de experiência.

A origem da palavra experiência provém do latim onde o prefixo ex de exterior, tem também per, do qual tem significado com travessia, passagem, caminho, etc. Assim é introduzido o significado do termo experiência, como experimentar - de acordo com sua origem latina ex/periri, também pode ser observado pelo o radical periri, "perigo". Ou seja, o ato de passar, num primeiro sentido, entendido "princípio de passagem", com vista para mais que esse passo, uma aventura, com questões incertas, de risco, ou perigo.

O sujeito da experiência, é entendido como um território de passagem em que algo passa e, ao passar, deixa seus vestígios, suas marcas. Para isto, Larrosa (2011) defende que o sujeito da experiência seja paciente, passional, e não se apresenta sempre de pé, firme, ereto, e seguro de suas opiniões, de si mesmo; não se diz por um sujeito definido por seus sucessos ou por seus poderes, mas um sujeito que se entrega para os dizeres que a experiência tem para lhe oferecer.

\section{LUGAR DE EXPERIMENTOS}

Atelier ${ }^{1}$ é um termo francês utilizado para designar "estúdio", "oficina de marceneiro". Entende-se por atelier um lugar de trabalho onde pessoas com vontade de criar possam experimentar, manipular e produzir variados tipos de arte. Para Romagnolo e Spaniol (2012, p. 16), “o que se espera de um ateliê é que, neste espaço, não se reproduza os modelos de representação do poder existentes em outros espaços da sociedade". Por se tratar muitas vezes de obras únicas, os autores destacam que a vida no ateliê fertiliza a imaginação e educa as emoções e os sentidos ampliando, significativamente, as possibilidades. Neste sentido, define-se por atelier, um espaço onde se tenha liberdade de inventar coisas de que o artista idealiza, as quais o mercado não pode oferecer, pois este, segue o fluxo da reprodução de objetos.

O Atelier Coreográfico, assim, configura-se num espaço que permite aflorar a criatividade. Aliado à dança, e consequentemente, à arte, aspirou não somente ao desenvolvimento de uma sequência coreográfica, mas almejou ser um espaço que se tornasse um campo de experiências singulares para todas as envolvidas.

Os critérios de seleção contaram com a inscrição de mulheres que participaram regularmente da atividade "Dança e Expressão Corporal", do programa UCS ${ }^{2}$ Sênior, pelo tempo mínimo de dois semestres letivos. Estas, deveriam inscrever-se gratuita e voluntariamente no Projeto de Extensão intitulado Atelier Coreográfico, projeto este ofertado em parceria com o

\footnotetext{
${ }^{1}$ A pesquisadora preferiu preservar a originalidade das fontes, onde ora a literatura apresenta a grafia atelier, ora ateliê. No entanto, para esta pesquisa se optou pelo termo atelier a fim de manter a escrita original da palavra.

${ }^{2}$ A sigla UCS é uma abreviação utilizada pela instituição Universidade de Caxias do Sul
} 
O envelhecimento feminino entre costuras: o atelier coreográfico como possibilidade de experiência.

Programa UCS Sênior, durante o semestre 2016/4. A amostra contou com a participação de 12 mulheres, com idades entre 52 e 68 anos. Dentre o grupo de mulheres participantes, a metade já realizava a atividade de Dança e Expressão Corporal desde o seu início, ou seja, há quase quatro anos; outras no entanto, encontravam-se no segundo semestre.

Dessa forma o Atelier Coreográfico teve como proposta inicial pensar o corpo cênico de mulheres idosas, que dentro de seus olhares para si, pudesse voltar o olhar do outro para esse corpo com uma percepção um pouco mais minuciosa. No espaço das aulas foram abordadas como referência as práticas da Dança Contemporânea, onde a mesma, não se apoia em técnicas ou movimentos específicos, mas permite ao intérprete/bailarino autonomia para construir suas próprias partituras coreográficas a partir de métodos e meios de pesquisa. Nesse caminho, Azevedo (2008), coreógrafo, bailarino e diretor do Núcleo de Experimentação Coreográfica do Porto, explica que: "Na dança contemporânea não existe um corpo ideal, como na dança clássica." (AZEVEDO, 2008).

Os artesãos aqui foram mulheres idosas que, com a assistência de um professor, produzem, reproduzem, interpretam e reinterpretam movimentos para compor a obra: uma dança de corpos reinventados em que se funde um imaginário fantástico com sonhos reais, valores e desejos de senhoras representados no palco. Assim podem ser resumidos o processo (que envolve aulas de exploração de movimentos corporais e expressão cênica) e o produto (coreografia) decorrente das aulas.

\section{O QUE DANÇOU: AS EXPERIÊNCIAS QUE ATRAVESSARAM O CORPO}

Nossas experiências contam a respeito de quem somos hoje, e através delas podemos suprir o pouco alcance de nossa voz em direção ao mundo. Dessa forma é possível fazer juízo à fala de Martha Graham (1991, p.8) quando ela nos diz que: "O corpo diz o que as palavras não podem dizer." A maneira pela qual nosso corpo se comporta depois de algumas experiências, talvez possa dizer o porquê de determinados modos de pensar, agir e ser. É a partir delas que podemos nos reconhecer enquanto processo de vida em vida, presente e inacabado; em desenvolvimento. Processo que percorreu e continua a percorrer espaços que nos proporcionam vivenciar o que ainda não vivenciamos. Nesses, não possuímos familiaridades, não sabemos sobre nós mesmos.

Nesse sentido, as experiências que atravessaram essas mulheres idosas foram organizadas nesta pesquisa, a partir de três pilares, a saber: a família, a escola e o casamento. A ideia de organizar as experiências individuais em pilares coletivamente compartilhados pelo grupo apresentou como objetivo principal a tentativa de compreender melhor o que cada uma trouxe 
O envelhecimento feminino entre costuras: o atelier coreográfico como possibilidade de experiência.

consigo de seus processos, e então, tornar inteligíveis tais informações. Interpretar a complexidade dessas memórias exigiu-nos, sobremaneira, reconhecer que esses processos culturais são históricos tanto quanto atuais na trajetória desses corpos. Em outras palavras, tal interpretação convidou-nos a reconhecer estes corpos, que hoje idosos, mas ainda em processo, não podem ser observados sob apenas uma ótica: a do hoje. Existe, em cada um, um tempo que foi, um tempo que é, e um que será.

A instituição família apareceu como uma experiência que traz consigo um legado marcado por muitas questões. Além de estar profundamente ligada às relações de sentimentos e afetos de diferentes tipos; doutrinou por muito tempo os conceitos do que poderia se afirmar como certo ou errado. Em um dos depoimentos sobre o pilar família, a Aluna A (2016, p 1.) esclarece que: "Eu me esforçava muito pra ter sempre as ações corretas, pra não incomodar, pra ser... Enfim, o que eles esperavam de mim".

A partir desta fala, Biroli (2014, p.7) explica que: "As experiências que temos das relações familiares são singulares, íntimas e fundamentais para percepção de quem somos, isto é, para as nossas identidades." A este corpo, que atravessado por experiências tão singulares de sua família carregadas estas, sobretudo, pela presença de uma autoridade externa bastante coercitiva, reservou-se, por muitos anos, a possibilidade de oferecer ao mundo aquilo a que fora educada: o esquadrinhamento de pensamentos e ações. Nesse sentido, as experiências que atravessaram esse corpo, são frutos de uma identidade construída a partir da docilidade (FOUCAULT, 2010) de suas formas de se conceber e se expressar, advindas de uma educação que transparece hierarquias muito bem definidas. O exercício de falar sobre suas memórias mostrou que o passado traz à tona experiências que ainda moram naquele corpo e que o constituem como ser no mundo. É possível identificar estas marcações corporais nas palavras da Aluna A (2016, p.1), quando ela afirma que: "Mesmo depois de eu ter tomado consciência, isso é uma coisa que ainda tem aquele lugarzinho". E continua:

\footnotetext{
"Porque na verdade, aquilo não era uma coisa minha, espontânea, era um esforço, um trabalho que en fazia, pra não incomodar a mãe, pra ter atenção. Isso tem um custo muito grande pra gente, eu tive momentos muito bons em família, muito alegres, mas isso é uma coisa que me marcou muito e assim... Pro resto da vida" (Aluna A, 2016, p. 1).
}

Os papéis desempenhados para agradar e para suprir a necessidade de ter a atenção se desenvolvem a partir da presença continua diante da mãe, da qual origina e caracteriza estes papeis idealizados e por conseguinte, desempenhados, em representações (GOFFMAN, 2009) como princípio de determinados modos de comportamento. Representações essas, que desencadeiam experiências que podem deixar marcas profundas e mesmo assim, serem invisíveis 
O envelhecimento feminino entre costuras: o atelier coreográfico como possibilidade de experiência.

aos olhares de fora, que no decorrer do tempo ainda podem ser estar implícitas na corporeidade (MERLEAU-POUNTY,2006) e revisitadas pelas memórias de uma época que ainda vive nas lembranças e que ainda atravessam o corpo.

Se tratando da instituição criada para a sociedade - a escola, a Aluna G manifesta a seguinte expressão:

\footnotetext{
"Eu não gostava da escola. Porque na minha casa, minha mãe sempre diæia que eu era burra, que en não ia entender nada, mas eu ia pra escola só pra não estar com ela. [...] Mas na escola, como eu não podia bater em minha mãe, eu batia em meus colegas” (Aluna G, 2016, p2).
}

Diante desta fala, Amado (1999) esclarece que quando falamos de fatores que provocam a indisciplina, não falamos de um mesmo fenômeno, mas de uma diversidade de fenômenos por detrás de uma mesma significação, ou seja, que neste caso a indisciplina era uma decorrência do problema maior: a falta de atenção e de carinho não ofertados pela família, principalmente pela mãe.

A fala proferida pela Aluna G $(2016$, p.2) relata suas ações e o porquê delas: "Eu tirei dentes, fraturei mãos, mas porque eu sou uma pessoa, e eu tenho um lugar no mundo, eu vou fazer o que eu quero fazer, e não o que os demais querem fazer de mim". Este discurso nos convida a refletir sobre esse lugar no mundo, esse lugar de atores sociais, que estão a todo momento se afirmando, e reafirmando. Ao assumirmos posturas diferentes, diante de lugares ou situações, Goffman (2009) nos convida a refletir sobre o conceito de representação. Sua aplicabilidade é bem visível aqui, no momento em que a Aluna G coloca-se como autora de sua vida, compreendendo as demandas que advém das exigências externas, e refutando-as.

No pilar casamento a Aluna I (2016, p.4) conta que: - "Eu tinha uma vida, que men esposo era doente, problemático e tal. A minha vida era, meu marido e minhas filhas. Eu não tinha outra vida. Então foi uma vida muito contida, muito reprimida.”. A partir desta fala, Canezin (2007) aponta que por muito tempo a única realização possível para mulher era o casamento, e sua condição imposta pela lei e pelos costumes, era de que: crescia submissa ao pai e continuava submissa ao marido. Por este fato, cabe olhar para esse corpo atravessado de experiências reprimidas por uma relação, numa perspectiva de que este vivia uma vida que não falava de seus desejos e anseios, mas que reproduzia o que seu companheiro desejava. O corpo aqui, não se sentia livre para viver suas próprias vontades, para se constituir no mundo, para experienciar numa relação de troca aquilo que se pode aprender e oferecer, mas se colocava a disposição da vontade de outros, por isso, a contenção e a repressão de uma vida por tanto tempo.

A partir dos resultados encontrados neste estudo, a pesquisa de Barbosa, Matos e Costa (2011), materializada no ensaio intitulado "Um olhar sobre o corpo: o corpo ontem e hoje", se 
O envelhecimento feminino entre costuras: o atelier coreográfico como possibilidade de experiência.

encaminha para uma perspectiva semelhante a qual este estudo encontrou na realidade vivenciada. Aquele ensaio, publicado e desenvolvido na Universidade do Porto, apresentou como objetivo retratar o corpo e seus aspectos sociais e culturais que contribuíram para a forma como este pôde ser olhado e representado na sociedade portuguesa. Como principais resultados, o estudo concluiu que é através do corpo que expressamos os efeitos e os significados das diferentes relações que tiveram ou que temos, ou seja, a existência corporal é imbuída num todo relacional e cultural, aberta e dinâmica, e não individual.

\section{UM CONVITE PARA DANÇAR: O ATELIER COREOGRÁFICO COMO UMA NOVA EXPERIÊNCIA}

Cabe, neste momento, fazermos a interpretação de nossa realidade à luz de nosso referencial teórico. Percorrer o conceito de experiência, no sentido aqui trazido por Jorge Larrosa Bondía, nos exigiu um olhar atento aos corpos silenciosos que gritavam mensagens em seus movimentos, e ao mesmo tempo, uma escuta atenta, às vozes que ora silenciavam, ora evidenciavam suas mensagens incorporadas nas entrelinhas dos seus sons.

Para uma breve discussão a partir das falas das alunas do Atelier Coregráfico, categorizamos três tipos de experiências: a) Experiência de Oportunidade; b) Experiência de Liberdade; c) Experiência de Desafio.

\section{Uma Experiência de Oportunidade}

\footnotetext{
"Eu diria assim: que a gente está se permitindo faz̧er coisas que talvez a gente não pode faz̧er quando a gente tinha essa idade dos 20 e poucos anos, porque não se tinham oportunidades. A gente está permitindo ao nosso corpo mostrar que a gente é capaz. Porque realmente, eu acho que a gente está se entregando" (Aluna B, 2016, p.1 grifo nosso).
}

A experiência de oportunidade tornou-se inteligível na fala das alunas, no momento em que estas qualificaram o espaço do Atelier Coreográfico como um lócus de experiências singulares. Este lugar, ocupado pelo Atelier Coreográfico em suas vidas, sugere que houve a possibilidade de, corporalmente, dar sentido ao que estas mulheres aspiravam e sentiam em silêncio. $O$ ato de "sentir através movimentos", ou seja, o que estes corpos puderam experimentar a partir da oportunidade gerada pela vivência em questão, pôde ser encontrado na fala da Aluna C (2016, p.1), quando a mesma se refere ao seu corpo como o palco onde a experiencia de oportunidade encontra a possibilidade de realizar-se: "[É a oportunidade] de derrubar barreiras, de ver que apesar da idade, com certo esforço, tu consegue superar os teus limites." 
O envelhecimento feminino entre costuras: o atelier coreográfico como possibilidade de experiência.

Corroborando com esse pensamento, utiliza-se da proposta da "poética da oportunidade", apresentada por Silva (2009), na qual o autor destaca que tal significação faz-se quando o dançarino toma proveito das oportunidades que emergem do seu "fazer dançante". Nesta perspectiva, a improvisação é abordada de maneira coerente e organizada e imprime sentido para aquela possibilidade de se mover. Em outras palavras, essa nova movimentação, que nasce do encontro gerado pela oportunidade e significação, não pode ser compreendida como um mover-se sem significação, longe de um sentido idealizado.

\title{
Uma Experiência de Liberdade
}

\begin{abstract}
"Eu além de oportunidade, vejo liberdade. O lugar que eu mais me sinto livre, porque eu circulo muito, em bastantes lugares, a minha semana é cheia. E aqui é o lugar que eu mais me sinto livre, sabe. Por isso, eu posso estar aonde eu tava, cheguei aqui atrasada, mas en venho! Que é o lugar que eu o consigo me colocar, me expressar. Meu corpo se expressa, eu gosto, gosto mesmo. Tem bastante abraço, bastante beijo, bastante mão dada, toque. Isso aí não tem lugar. Não tem." (Aluna J, 2016, p.1).
\end{abstract}

A liberdade hoje é legitimada como um estado digno de todos. As experiências da família, da escola e do casamento, podem vir a contribuir para este corpo, que se identifica a uma gaiola fechada e trancada por estas questões que limitam a sensação de liberdade, ou seja, da expressão. Limites estes, que impedem o corpo de realizar suas próprias ações, deixando marcas. Em contrapartida, o Atelier Coreográfico surge nas falas como um espaço que permitiu a estas idosas o sentimento de liberdade, ou seja, possibilitou a experiência de sentirem-se autoras de seus pensamentos, desejos, movimentos e de suas vontades. Tal afirmação pode ser percebida na fala da Aluna C, (2016, p.1) que segue: "porque aqui tu pode ser tu mesma, tu não tem a cobrança de um filho, de um marido, de ninguém.”. Na mesma direção, encontramos a experiência de liberdade implícita na seguinte expressão trazida pela Aluna F (2016, p.2): "É uma libertação de amarras, de preconceitos, de insegurança, de um monte coisa. É como se tu te livrasse de tudo isso que tu se transforma.”. Dessa forma, as falas trazidas pelas alunas do grupo, indicaram que a realização de movimentos expressivos, diferenciados daqueles já conhecidos e sobretudo, sem padrões de execução rígidos e definidos, proporcionaram a si a sensação de liberdade que se configurou, por sua vez, em uma intensa experiência.

Nesse caminho, é possível andar junto da proposta Francis (1994) citado por Castro (2014, p.31) onde ele afirma que Isadora Duncan se tornou um forte ícone de sua época também por mudar o posicionamento da mulher no processo artístico: "Ela revelou a sensação de liberdade do corpo feminino na radicalidade de suas performances. A transformação da dança dela estava enraizada em sua luta para desarmar o poder da civilização em dominar e controlar o corpo.”. A fim de libertar o corpo feminino, Isadora Duncan contribuiu significadamente com o 
O envelhecimento feminino entre costuras: o atelier coreográfico como possibilidade de experiência.

desenvolvimento de movimentos naturais, ou seja, movimentos que pudesse romper o aprisionamento do corpo. O movimento, na experiência de liberdade é a possibilidade de se colocar e de falar o que não pode ser dito com o som da voz, mas que de outra forma se encontram caminhos para saciar a necessidade de expor suas expressões e de dar forma e significado aos sentimentos desses corpos femininos.

\section{Uma Experiência de Desafio}

\footnotetext{
"Em relação ao Atelier Coreográfico, pra mim foi um desafio de movimentos. Foi muito desafiante. Porque quando tu dança lá, tu coloca aquela música e tu sabe quais passos da coreografia, tu vai. Mas aqui, pra mim, é muito diferente, porque aí cada movimento, daqueles negócios que tu faz, tu sente teu corpo, que tu se solta, eu acho, de coisas que a gente tem. [...]” (Aluna I, 2016, p.3).
}

A dança possui uma peculiaridade que a deixa ainda mais interessante: o desafio. $\mathrm{O}$ desafio de quem não sabe em que solo pisa, o que irá encontrar, e principalmente, o que isso irá provocar em sua vida. O desafio aqui é visto como experiência, que na medida em que provoca uma ação, também gera uma reação. Ao incorporarmos nosso referencial teórico, podemos entender que a experiência de desafio é um movimento de ida e volta, ao ir, requer um acontecimento, ou seja, desafio de abertura, enquanto que na volta, gera efeitos destes desafios nas mulheres, naquilo que sentem, pensam e sabem.

A este fato, o interessante é perceber que o movimento não fala a partir da ação que aquele corpo executa por si só, mas que desenvolve um emaranhado de "outras experiências" que fazem com que aquele corpo execute determinados movimentos da sua própria maneira, ou seja, exprime em seu corpo, de alguma forma, os dizeres de suas experiências corporais desenvolvidas ao longo do tempo. Cabe compreender, como esse corpo absorve o movimento, do ponto de vista de quem cria - simples, porém de quem executa complexo e desafiador.

Ao retratar o movimento em palavras, compete mencionar esta experiência de desafios como uma ação modificadora, transformadora, e principalmente, uma transgressão destes corpos femininos. Filho (2003) aponta em seu estudo uma abordagem singular sobre reconhecer as transgressões em termos de afirmações positivas. Em outras palavras, o autor convida-nos a reconhecer o ato de transgredir, como a ação humana que visa ultrapassar, atravessar, exceder nossos próprios conceitos.

A transgressão pode ser reconhecida nesses corpos idosos femininos como a possibilidade de expressão de seus sentimentos. Na fala da aluna $\mathrm{G}$ (2016, p.2), tal possibilidade de expor o que se sente através dos movimentos torna-se realidade: "eu acho que fazendo isto, en encontrei, que meu corpo, ele fala por si mesmo, e ele pode viver, vibrar, ele pode expressar através das notas da 
O envelhecimento feminino entre costuras: o atelier coreográfico como possibilidade de experiência.

música o que ele sente, ele pode jogar a raiva, ele pode expressar a tristeza. [...] É querer dar mais do que às vežes pensamos que temos".

Portanto, entendemos a transgressão como as mudanças a partir dos desafios que aparecem pedindo ainda mais do que achamos que temos para oferecer. Assim, Guimarães Rosa (1994 p.23) completa este significado com a seguinte expressão: "O mais importante e bonito, do mundo, é isto: que as pessoas não estão sempre iguais, ainda não foram terminadas - mas que elas vão sempre mudando. Afinam ou desafinam." E completaríamos: mesmo depois de velhas.

\section{E POR FIM...}

Tornou-se possível identificar que a vivência gerada a partir das aulas do Atelier Coreográfico fez emergir uma nova experiência de vida para o grupo de participantes, sustentada por três pilares principais: a oportunidade, a liberdade, e o desafio. A dança contemporânea despertou que estas mulheres encontrassem sentidos aos movimentos, que antes desinteressados e sem significação, agora oportunizaram os dizeres desses corpos envelhecidos.

É interessante compreender por fim, que o corpo nunca esteve definido, ou seja, pronto e acabado. O movimento toma o lugar do discurso e derruba paradigmas, acentua os desafios, oportuniza a fala, e liberta as amarras para a entrega do corpo a outras experiências.

Costurar os caminhos da vida não constitui uma tarefa fácil, mas desafiadora. No entanto, no avançar de nossa juventude, o convite que recebemos da vida é o de acolhermos nossas experiências e compreendê-las como partes constituintes de nós mesmos, enquanto seres em construção. Esse olhar, em constante transformação, nos fez entender que o Atelier Coreográfico foi um processo enriquecedor que representou, de fato, uma experiência latente e vibrante na constituição destas mulheres idosas.

\section{REFERÊNCIAS}

Aluna A. 2016. Entrevista concedida à Amanda Khalil Suleiman Zucco. 26 set. 2016. Caxias do Sul, RS. Transcrição: Amanda Khalil Suleiman Zucco.

Aluna G. 2016. Entrevista concedida à Amanda Khalil Suleiman Zucco. 26 set. 2016. Caxias do Sul, RS. Transcrição: Amanda Khalil Suleiman Zucco.

Aluna I. 2016. Entrevista concedida à Amanda Khalil Suleiman Zucco. 26 set. 2016. Caxias do Sul, RS. Transcrição: Amanda Khalil Suleiman Zucco.

Aluna B. 2016. Entrevista concedida à Amanda Khalil Suleiman Zucco. 27 out. 2016. Caxias do Sul, RS. Transcrição: Amanda Khalil Suleiman Zucco. 
O envelhecimento feminino entre costuras: o atelier coreográfico como possibilidade de experiência.

Aluna C. 2016. Entrevista concedida à Amanda Khalil Suleiman Zucco. 27 out. 2016. Caxias do Sul, RS. Transcrição: Amanda Khalil Suleiman Zucco.

Aluna J. 2016. Entrevista concedida à Amanda Khalil Suleiman Zucco. 27 out. 2016. Caxias do Sul, RS. Transcrição: Amanda Khalil Suleiman Zucco.

Aluna F. 2016. Entrevista concedida à Amanda Khalil Suleiman Zucco. 27 out. 2016. Caxias do Sul, RS. Transcrição: Amanda Khalil Suleiman Zucco.

Aluna I. 2016. Entrevista concedida à Amanda Khalil Suleiman Zucco. 27 out. 2016. Caxias do Sul, RS. Transcrição: Amanda Khalil Suleiman Zucco.

Aluna G. 2016. Entrevista concedida à Amanda Khalil Suleiman Zucco. 27 out. 2016. Caxias do Sul, RS. Transcrição: Amanda Khalil Suleiman Zucco.

AMADO, João da Silva. Indisciplina na aula: regras, tarefas e relação pedagógica. Psicologia, Educação e Cultura, Lisboa, v. 3, n. 1, p. 53-72, 1999.

AZEVEDO, Joclécio. O que é dança contemporânea?. Jornalismo Porto Net. Ciências da Comunicação da Universidade do Porto. Porto, 2008.kiçokç;plll

Disponível em: <https://jpn.up.pt/2008/12/22/o-que-e-a-danca-contemporanea/> Acesso em: 10 de outubro de 2016.

BARBOSA, M.R.; MATOS, P.M.; COSTA, M.E. Um olhar sobre o corpo: o corpo ontem e hoje. Psicologia \& Sociedade, v.23, n.1, p.24-34, 2011

BAUMAN, Zígmaund. Amor líquido: sobre a fragilidade dos laços humanos. Rio de Janeiro: Jorge Zahar Editor, 2004.

BIROLI, Flávia. Família moderna. In: Família: novos conceitos. São Paulo: Editora Fundação Perseu Abramo, 2014. Disponível em: < http://www.fpabramo.org.br/forum2013/wpcontent/uploads/2014/08/colecaooquesaber-05-com-capa.pdf> Acesso em: 10 out 2016.

CANEZIN, C. C. A Mulher e o Casamento: da Submissão à Emancipação. Revista Jurídica CESUMAR. Mestrado, Maringá: v. 4, n. 1, p. 143-156, 2004.

CASTRO, Lina Frazão de. O corpo em estado de transparência: abordagens didáticas em dança Brasília. 2014. Dissertação (Mestrado em Artes) - Universidade de Brasília, Programa de Pós Graduação em Artes, Brasília, 2014. Disponível em: < http://repositorio.unb.br/bitstream/10482/15771/1/2014_LinaFrazaoCastro.pdf> Acesso em: 22 out. 2016.

FILHO, Alípio de Sousa. Cultura, ideologia e representações sociais. In: CARVALHO, Maria do Rosário; PASSEGGI, Maria da Conceição; SOBRINHO, Moisés Domingos (Org.).

Representações sociais. Mossoró: Fundação Guimarães Duque, 2003. p. 71-82.

FOUCAULT, Michel. Vigiar e Punir. 38 ed. Petrópolis, RJ: Vozes, 2010.

FORTIN, Sylvie. Contribuições possíveis da etnografia e da auto-etnografia para a pesquisa na prática artística. Revista Cena, Porto Alegre, n. 7, Editora: UFRGS, p. 78-79, fevereiro 2009. 
O envelhecimento feminino entre costuras: o atelier coreográfico como possibilidade de experiência.

GERHARDT, Tatiana Engel. Notas para a elaboração e o desenvolvimento do método de observação. In: GERHARDT, T. E.; SILVEIRA, D. T. (Orgs). Métodos de Pesquisa. Porto Alegre, RS: Editora da UFRGS, 2009, p. 101-103.

GOFFMAN, Erving. Representações. In: A Representação do Eu na Vida Cotidiana; tradução: Maria Célia Santos Raposo. 13ª Edição. Petrópolis: Editora Vozes, 2009.

GUIMARÃRES, Rosa, J. Grande Sertão: Veredas. Rio De Janeiro: Nova Aguilar, 1994.

LARROSA, Jorge. Experiência e Alteridade em educação. Revista Reflexão e Ação, Santa Cruz do Sul, v.19, n2, p.04-08, jul./dez. 2011.

MERLEAU-PONTY, M. Fenomenologia da Percepção. 3a ed. São Paulo: Martins Fontes, 2006.

MINAYO, Maria Cecília de Souza (org.). Pesquisa Social: teoria, método e criatividade. 18 ed. Petrópolis, RJ: Vozes, 2001.

NAVAS, Lenora Cássia. Arte da composição: teatro do movimento, págs 179-195- por BERTÉ, Odailso. Dança contempop: corpos, afetos e imagens (mo)vendo-se. Santa Maria: Ed. da UFSM, 2015.

SILVA, Hugo Leonardo da. Poética da Oportunidade: estruturas coreográficas abertas à improvisação. Salvador: EDUFBA, 2009.

SPANIOL, Dorotéa Kerr; ROMAGNOLO, José Sérgio Mauro. Atelier Permanente, Caderno de Formação, In: KERR, Dorotea. (Org.). Caderno de Formação. São Paulo: Culturac Academica Editora, 2012, v. 5, p. 1417.

ORLANDI, Eni Puccinelli. Análise de Discurso: princípios \& procedimentos. 8. ed. Campinas: Pontes, 2009. 100p.

TRAD, Lab. Grupos focais: conceitos, procedimentos e reflexões baseadas em experiências com o uso da técnica em pesquisas de saúde, Physis, 2009.

TEIXEIRA, L, I; PÖRTNER, C. G. Por uma experiência legítima: o local do acontecimento na contemporaneidade. Revista EnsiQlopédia - FACOS/CNEC Osório v.10, n1 - OUT/2013

THIOLLENT, M. Metodologia da pesquisa-ação. São Paulo: Cortez \& Autores, 1988. 